\title{
Violence within mental health services: how to enhance risk management
}

This article was published in the following Dove Press journal: Risk Management and Healthcare Policy

\author{
Margaret O'Rourke' \\ Conal Wrigley ${ }^{2}$ \\ Sean Hammond ${ }^{3}$ \\ 'School of Medicine, University \\ College Cork, Cork, Ireland; '2INFANT \\ Research Group University College \\ Cork, Cork, Ireland; ${ }^{3}$ School of \\ Applied Psychology, University \\ College Cork, Cork, Ireland
}

\begin{abstract}
This paper aims to present best practice in risk management within mental health services. Its purpose is to explore the prevalence of violence within mental health services, to examine the nature of risk, highlight lessons learned and guidance published on safer services, and to identify ways to enhance risk management in mental health care. We reflect on current health care practices in the UK, England and Wales, and Ireland and refer to research and practice from other jurisdictions internationally where it exists.
\end{abstract}

Keywords: violence, mental health, risk management, best practice

\section{Introduction}

Violence within health services is a growing concern for the safety of patients/service users and that of clinical and nonclinical staff members within different mental health services. A number of recent studies have identified a significant increase in the number of reported incidences of violence and aggression toward staff and other service users. ${ }^{1-3}$

One in four adults and younger in the UK and Ireland are affected by mental health issues. ${ }^{4}$ Similar rates apply internationally. At any one time, 8 in every 100 people will see a general practitioner (GP) or family doctor in connection with a diagnosed mental health problem, 2 people in every 100 will be living in the community and receiving treatment from a psychiatrist or community mental health team. Once a person has contacted their GP, their needs are usually met with the GP/primary care team practice; less than $10 \%$ of cases are referred to secondary care within mental health service.

Mental health issues can have a profound effect on those who are directly involved with the care of the patient. An estimated 6 people, which may include loved ones such as family, partners, friends, and carers, may be affected by the debilitating consequences of a mental health issue. Additionally, cognitive, social, and emotional functions and skills can be impacted upon due to ongoing issues with mental health. ${ }^{5}$

\section{Definitions of risk}

Risk may be defined as the chance or possibility of loss or bad consequence. At risk is defined as being exposed to danger or hazards. ${ }^{5}$

\section{Risk assessment}

Risk assessment may be defined as the systematic collection of information to determine the degree to which harm (to self or others) is likely at some future point in time. Risk
Correspondence: Margaret O'Rourke School of Medicine, UCC Brookfield Health Sciences Complex, College Road, Cork, Ireland TI2 DXOI

Tel +353214901595

Email m.orourke@ucc.ie 
assessment must be explicit and fluid and will normally be short term and take into account a balance of factors (hazards and protectors). ${ }^{4,6}$

\section{Risk prediction}

The assigning of a probability to a patient, indexing the likelihood of that patient to commit harm to self or others, eg, suicide/self-harm or a violent offense (criminal or otherwise), within and/or outside hospital. ${ }^{7-9}$

\section{Risk management}

The implementation of a set of values and principles integrated with a set of operational procedures and supports surrounding a patient or client that enable a dynamic sensitivity to the individual's needs, vulnerabilities, and evolving behaviors. The purpose of these procedures being risk reduction and prevention and the provision of safe, sound, supportive services. ${ }^{4,10}$

It is important to be clear about what we mean when we examine risk in relation to mental health issues. While the primary focus of the current paper is risk of violence, it must be acknowledged that there are 4 clear areas of risk that are relevant for consideration when dealing with people with mental health issues: ${ }^{4}$

1. Dangerousness: Violence or causing harm or danger to others or a propensity for encouraging/involving others in the causing of harm or injury to others.

2. Mental instability: At risk of self or others because of fluctuating and/or unpredictable mental health function especially in relation to command hallucinations and other "at risk" psychotic or disturbed phenomena.

3. Self-harm/suicide risk: At risk from self, intentional injury or killing oneself; actions/behaviors destructive to one's own safety or health.

4. Vulnerability: At risk of or exposed to damage or harm through personal or external factors (eg, naïveté, low insight, family, social/community pressures, in care, poverty, homelessness or other resource or capability deficits).

This paper is concerned with violence risk only.

In the USA, a survey conducted by the Department of Justice's National Crime Victimization identified the rate of nonfatal, job-related crime to be 12.6 per 1,000 workers. The survey determined custodial workers were the victims of the highest rate of violence $(69$ per 1,000$)$ followed by psychiatrists and mental health care professionals (68.2 per 1,000). Physicians $(16.2$ per 1,000$)$ and nurses $(21.9$ per 1,000$)$ were other occupations to have suffered from physical attacks of service users. ${ }^{11}$ Those who work recurrently with service users are more likely to suffer from violent or aggressive behavior, ${ }^{12}$ and $50 \%$ of those who are undertaking a 4 year training as psychiatry residents will be physically attacked. ${ }^{13}$

In the UK, there were 60,000 assaults reported on National Health Service (NHS) staff between 2011 and 2012. ${ }^{14}$ Sixtynine percent $(43,699)$ of these assaults were conducted in mental health and learning disability settings, while $26 \%(16,475)$ involved acute hospital staff. The remaining $6 \%$ of assaults were against ambulance staff (3\%) and primary care workers $(3 \%)$. More recently, $14 \%$ of all NHS staff reported some experience of physical abuse from a service user in 2014, which was reduced from $15 \%$ in $2013 .{ }^{15}$ In light of these figures, enhancing risk management skills in staff is critical for the reduction of violent abuse within mental health and other settings.

\section{Materials and methods}

The current paper reviews the current state of affairs in mental health risk management but this is not a systematic review in the usual sense. ${ }^{16,17}$ It is informed by long experience within the mental health field and should be viewed more as a position paper than a systematic review. In collating data for the paper, we carried out searches of the literature using Medline and EBSCO search engines. Key words used were "Mental Health," "Risk Management" and "Risk Assessment." In addition a search of government reports and inquiries was carried out.

\section{Results}

This section highlights difficulties in determining prevalence and attempts to present a distillation of the evidence available in 3 areas of inquiry:

1. Violence in general health care settings

2. Violence in mental health services, and

3. Violence in community mental health settings.

The objective is to arrive at informed suggestions for reducing or preventing violence and enhancing risk management in mental health care settings.

\section{Difficulties in determining prevalence}

Although the incidence of violent behavior within psychiatric and emergency departments is well documented, there is relatively little information available for the frequency of violent acts within primary care or community settings. ${ }^{18}$ A recent review indicated that only 14 of 113 studies reported violence within community settings. ${ }^{19}$ The complexities of identifying 
accurate prevalence rates of violence within mental health services are convoluted further through varying definitions of violent behavior within the research that may or may not include verbal aggression toward service providers ${ }^{20}$ and selfreported feelings of unsafeness. ${ }^{19}$ Additionally, studies have shown there is a large number of violent incidents which go unreported. ${ }^{21,22}$ Further, the occurrence of violent behavior that constitutes self-injury by service users has according to some researchers ${ }^{15}$ a far greater rate of prevalence while research findings ${ }^{23}$ suggest that most mentally ill people present a greater risk to themselves than to others.

Despite these challenges, categorizing violent behaviors within mental health services allows researchers to indicate where risk factors occur and what type of factors are likely to predict and reduce the incidental rate of violent behaviors.

Table 1 summarizes the USA and UK figures for Homicide and Violence in Health care Settings using injury setting, injury style, injured party, and injury-related mental illness as categories for incidence and prevalence rates.

\section{Violence within different settings}

In a recent study of 280 employees from 6 emergency departments in the USA, $80 \%$ experienced some type of violent behavior in their current role. ${ }^{24}$ The prevalence of violence within elderly care services is largely unreported. ${ }^{25}$ However, with the rate of violent behavior in dementia patients reported at $96 \%$ of all cases followed over a period of 10 years, the number of violent incidents toward service providers is predictably substantial. Epidemiological studies indicate that $4 \%$ of the total employee population has at some point experienced an act of physical violence inflicted upon them. ${ }^{26}$ The majority of such acts have been committed toward nurses who are 3 times more likely to be victims of violent behavior than any other professional group. ${ }^{27}$

Table I Prevalence of homicide and violence in health care settings

\begin{tabular}{|c|c|c|c|c|c|}
\hline Country & Injury setting & Injury style & Injured party & Injury period & Source \\
\hline \multirow[t]{16}{*}{ United States } & $\begin{array}{l}\text { Health care and social } \\
\text { services }\end{array}$ & $\begin{array}{l}\text { Homicide through } \\
\text { violent acts ( } 27)\end{array}$ & $\begin{array}{l}\text { Health care and social service } \\
\text { workers }\end{array}$ & 2013 & $\begin{array}{l}\text { Bureau of Labor Statistics } \\
(20 \mid 4)^{45}\end{array}$ \\
\hline & Health services & Homicide (7) & Health care industry worker & 1999 & $\begin{array}{l}\text { United States Department } \\
\text { of Labor }(2000)^{46}\end{array}$ \\
\hline & Health services & $\begin{array}{l}\text { Homicide ( } 13 \text { per } \\
\text { annum) }\end{array}$ & Health care industry worker & $1994-1998$ & $\begin{array}{l}\text { United States Department } \\
\text { of Labor }(2000)^{46}\end{array}$ \\
\hline & Health services & Homicide (106) & Pharmacists (27) & $1980-1990$ & Goodman, Jenkins \& \\
\hline & & & Physicians (26) & & Mercy $(1994)^{47}$ \\
\hline & & & Nurses (18) & & \\
\hline & & & Nurse's Aids (17) & & \\
\hline & $\begin{array}{l}\text { Health care and social } \\
\text { services }\end{array}$ & $\begin{array}{l}\text { Workplace assault } \\
(23,540-25,630)\end{array}$ & $\begin{array}{l}\text { Health care and social service } \\
\text { workers }\end{array}$ & $2011-2013$ & $\begin{array}{l}\text { Bureau of Labor Statistics } \\
(20 \mid 4)^{45}\end{array}$ \\
\hline & Health services & $\begin{array}{l}\text { Victimization of } \\
\text { threats and assaults } \\
(1 \mathrm{I}, 370)\end{array}$ & $\begin{array}{l}\text { Health care and social assistance } \\
\text { workers }\end{array}$ & 2010 & $\begin{array}{l}\text { Bureau of Labor Statistics } \\
(2010)^{48}\end{array}$ \\
\hline & Health services & Victimization of & Custodial workers $(69$ per 1,000$)$ & $2005-2006$ & Friedman et al (2006) ${ }^{\prime \prime}$ \\
\hline & & threats and assaults & Psychiatrists and mental health & & \\
\hline & & $(12.6$ per 1,000$)$ & workers (68.2 per I,000) & & \\
\hline & & & Physicians (I6.2 per I,000) & & \\
\hline & & & Nurses $(21.9$ per 1,000$)$ & & \\
\hline & $\begin{array}{l}\text { Health services } \\
\text { (medical occupation) }\end{array}$ & $\begin{array}{l}\text { Victimization of } \\
\text { threats and assaults } \\
(150,300)\end{array}$ & Medical staff & $1992-1996$ & $\begin{array}{l}\text { United States Department } \\
\text { of Justice }(1998)^{49}\end{array}$ \\
\hline & $\begin{array}{l}\text { Health services } \\
\text { (mental health } \\
\text { settings) }\end{array}$ & $\begin{array}{l}\text { Victimization of } \\
\text { threats and assaults } \\
(94,300)\end{array}$ & Mental health occupations & $1992-1996$ & $\begin{array}{l}\text { United States Department } \\
\text { of Justice }(1998)^{49}\end{array}$ \\
\hline United & Health services & Physical assaults & Health care staff & 2015 & Health and Safety \\
\hline \multirow[t]{6}{*}{ Kingdom } & & $(4,697)$ & & & Executive $(2016)^{50}$ \\
\hline & Health care services & Assault $(60,000)$ & Health care staff & $2011-2012$ & Littlechild $(2012)^{14}$ \\
\hline & Health care services & Victimization of & Nurses ( $5 \%$ of all occupations) & 1994, 1996, & Health and Safety \\
\hline & & threats or assault & $\begin{array}{l}\text { Care workers }(2.8 \% \text { of all } \\
\text { occupations) }\end{array}$ & 1998 & Executive $(1999)^{51}$ \\
\hline & & & Other health professionals ( $1.4 \%$ & & \\
\hline & & & of all occupations) & & \\
\hline
\end{tabular}


A review of 424 studies of inpatient settings and violent behavior indicated the overall incidence of violent behaviors by service users was $32.4 \%$ in psychiatric hospitals. ${ }^{19}$ The research stated the number for forensic inpatients incidental rates would be proportionally higher because the risk of violence in acute hospitals was considerably greater. Dickens et $\mathrm{al}^{28}$ found 2,137 incidents of violence were reported by $42.9 \%$ of service users in forensic settings. Staff members were twice as likely to report incidents of violent or aggressive behavior toward other service users, while other studies have found staff and service users to be just as likely to be the victims of violent acts. ${ }^{29} \mathrm{~A}$ little under 400 service users of the high-secure setting reported 3,565 incidents of violence over a 16 month period - a staggering 9 incidents per person, and perhaps even more concerning was the incidents were conducted by a very small, disproportional amount of users within the service.

Violence toward service providers extends beyond inpatient care and forensic settings. Staff within GP services, residential units, community mental health teams, and public places work within settings that provide services to users with challenging behaviors. Social care workers who work within mental health services and residential work areas are more likely to be assaulted than care workers in other areas. ${ }^{30}$ In a survey of 2,000 social care workers, $10 \%$ reported difficult challenging behavior with $35 \%$ of these 200 reporting physical violence and another $49 \%$ reporting verbal abuse. ${ }^{31}$ The Health and Safety Executive in Ireland ${ }^{32}$ reported an incidental rate of 2,348 injuries to workers in nonresidential care units in 2010 and 2011, although the number of incidents could be extensively larger given the level of unreported acts of violence. ${ }^{33}$ More recently in a study of 402 Irish social care workers, $74 \%$ of workers reported experiencing some type of physical abuse in the last year, with workplace violence being a daily occurrence for some staff. ${ }^{34,35}$ Additionally, $60 \%$ of these respondents reported that their employer actively accepted violent acts within their services as part of the occupation. In conjunction with the continued daily occurrence of violence toward social care workers and the accepted cultural norm of violence within the workplace, there are significant costs placed upon the personal and professional well-being of social care workers in residential units and mental health settings.

This suggests that violence should be examined not just by incidents, contexts, injured party, and environments but also by looking more closely at the violent behavior and the clinical profiles of service users with a history of violent or aggressive behavior(s). Predisposing and precipitating factors may include demographic and premorbid psychosocial and clinical factors, criminal history, psychopathology, alcohol and/or substance misuse, treatment-related, suicidality. The data cited above also raise the question of placement and whether patients are adequately assessed, risk managed, and reviewed in services currently.

\section{Independent inquiries: lessons for safe practice}

The last decades of the 20th century saw over 100 reports of inquiry into the treatment and care of people with a diagnosis of mental disorder who have killed or been involved in violent incidents. Of note is the fact that many of the public inquiries highlight the same key areas of concern. Parker and $\mathrm{McCulloch}^{36}$ identified the critical factors involved and highlighted key issues as follows (in roughly descending order of importance or frequency):

1. Poor risk management

2. Communication problems

3. Inadequate care planning

4. Lack of interagency working

5. Procedural failures - both administrative and legal

6. Lack of suitable accommodation

7. Lack of resources

8. Substance misuse

9. Noncompliance with medication

10. Lack of involvement of carers

11. Minority ethnic issues, eg, staff being too ready to make incorrect and stereotypical assumptions about black service users from minority backgrounds.

The predictability and preventability of homicide incidents has also been investigated. ${ }^{37}$ The authors looked into public inquiries between 1988 and 1997 to examine if more appropriate risk assessment of people with mental illnesses who committed acts of homicide would have averted the outcome considered through the inquiry panels. The inquiries indicated that $27.5 \%$ were predictable, with $65 \%$ thought preventable. Sixty percent of the inquiries were found to have a history that contained violence and other associated risk factors for violence, which led the investigators to conclude that improved risk assessment would only have a slight role in reducing homicide. Mortality could be reduced through improved mental health care, irrespective of the risk of violence.

\section{The National Confidential Inquiry Lessons for Safer Practice}

The National Confidential Inquiry into Suicide and Homicide by People with Mental Illness (NCISH), was set up in 
1996 by the UK Governments' then Czar of Mental Health Professor Louis Appleby. This inquiry enabled mental health providers to report, confidentially and in a no blame context, on the failures and realities of mental health services and service users.

A total of 27,885 suicides were reported in 2016 by $\mathrm{NCISH}$ between 1998 and 2014, ${ }^{38}$ an average of 1,640 suicides per year related to primary and secondary service users of mental health services. Homicides related to patients totaled 1,277 in the same period, which averaged 75 homicidal incidents per year and equaled $11 \%$ of all homicidal convictions per capita. Studies have looked at dominant risk factors at the time of homicidal occurrence ${ }^{39}$ and found that $6 \%$ (31) of patients between 2005 and 2014 were under crisis resolution/home treatment. Thirty-one percent (204) committed an act of homicide following 13 weeks of service contact, while 21\% (141) acted between 5 and 13 weeks. The majority of acts were committed within 4 weeks of the perpetrator's last service contact (48\%). Within these 4 weeks, $42 \%$ of these services users had schizophrenia (131), $5 \%$ were inpatients, and $11 \%$ had been discharged, while $7 \%$ were under crisis resolution/home treatment team care $(16,31$, and 20 , respectively). Over half $(52 \% ; 334)$ were previously convicted of violent behavior and just under half $(48 \% ; 286)$ served a prison sentence. While $6 \%$ (36) had previously been admitted to a secure unit, $24 \%$ were involuntarily detained by services under the mental health legislation. The number of voluntary committals has significantly dropped over the last few years from 20 in 2005 to 8 in 2013 . Homicides committed by those with previous schizophrenic diagnoses accounted for 369 homicides between 2004 and 2014, which averaged 34 per year. Of these, $82 \%$ (303) had symptoms of psychosis at the time of offense.

The reported numbers of offenses related to homicidal acts by service users with current or previous diagnoses of schizophrenia fell gradually over the time period but peaked in 2013, when 40 cases of homicide were reported. The numbers of incidents have specifically risen in England over this period since 2009. However, the researchers believe it is difficult to find a determined pattern of causality for these findings with such few numbers and these numbers may be a result of "dual diagnosis" (ie, drug and alcohol use during acts of homicide), and these numbers are likely to reflect an increase in court processes in 2013.

Four percent (251) of the sample were diagnosed with personality disorders, and of these 35\% (89) were patients of mental health services at the time of the incident. In terms of alcohol and drug use, 74\% (464) had a history of alcohol misuse, while $78 \%$ (485) had a history of drug use. However, a gradual fall in numbers was shown during the report period. Twenty-five percent (158) of patients had a severe mental illness and comorbid drug use or alcohol dependence, which averaged 14 per year. ${ }^{38}$

\section{Current guidance on risk and risk management in the UK}

Nearly 20 years have passed also since the UK Government launched the National Service Framework for Mental Health (1999), which set out the standards for mental health services and for the professionals who provide them. It specifies what services and professionals should be aiming to achieve, how services should be developed and delivered, and how performance should be measured. Standard Five in particular refers to the need for effective risk management systems in relation to providing effective services for people with severe mental illness.

Individuals and organisations often take a 'fight or flight' approach to risk assessment and management. The former is characterised by over-reaction, rigidity, excessive controls and the identification of risk where none may exist. The latter can involve avoidance, complacency or the denial and minimisation of risk. Anxiety and other emotions can therefore exert a significant influence on risk assessment, management strategy, practice and policy. 5

Effective risk management is crucial to the provision of safe and good quality services. Good quality services recognize that risk should be managed within good quality and safe care management.

Safe practice requires the professional to have robust systems that allow valid, reliable, and retrospectively defensible risk assessment and management, for every patient, every time. ${ }^{5}$

In 2007 the Department of Health and Home Office issued Best Practice in Managing Risk. ${ }^{40}$ This Guidance identified 16 best practice points for effective risk management (from Department of Health, UK Guidance, June 2007) and highlighted the first point "Best practice involves making decisions based on knowledge of the research evidence, knowledge of the individual service user and their social context, knowledge of the service user's own experience, and clinical judgment." The Guidance then lists 4 "fundamentals" (summarized directly from the Guidance here) including:

1. Positive risk management as part of a carefully constructed plan is a required competence for all mental health practitioners. 
2. Risk management should be conducted in a spirit of collaboration and based on a relationship between the service user and their carers that is as trusting as possible.

3. Risk management must be built on recognition of the service user's strengths and should emphasize recovery.

4. Risk management required an organizational strategy as well as efforts by the individual practitioner.

Six "Basic ideas in risk management"

1. Risk management involves developing flexible strategies aimed at preventing any negative event from occurring or, if this is not possible, minimizing the harm caused.

2. Risk management should take into account that risk can be both general and specific, and that good management can reduce and prevent harm.

3. Knowledge and understanding of mental health legislation is an important component of risk management.

4. The risk management plan should include a summary of all risks identified, formulations of the situations in which identified risks may occur, and actions to be taken by practitioners and the service user in response to crisis.

5. Where suitable tools are available, risk management should be based on assessment using the structured clinical judgment approach.

6. Risk assessment is integral to deciding on the most appropriate level of risk management and the right kind of intervention for a service user.

Two important points on "Working with service users and carers"

1. All staff involved in risk management must be capable of demonstrating sensitivity and competence in relation to diversity in race, faith, age, gender, disability, and sexual orientation.

2. Risk management must always be based on awareness of the capacity for the service user's risk level to change over time, and recognition that each service user requires a consistent and individualized approach.

And 3 "Individual practice and team working" points

1. Risk management plans should be developed by multidisciplinary and multiagency teams operating in an open, democratic and transparent culture that embraces reflective practice.

2. All staff involved in risk management should receive relevant training, which should be updated at least every 3 years.
3. A risk management plan is only as good as the time and effort put into communicating its findings to others.

\section{Enhancing risk management in mental health services}

"The highest priority of health services should be the safety of patients in their care. Users of our mental health services are entitled to expect the protection they need, and all patients and service users should be protected from avoidable harm. Often risks are challenging to assess, as is the effectiveness of different interventions. Safe practice can only be achieved by adopting a rigorous learning culture." Sir Robert Francis QC (National Confidential Inquiry). ${ }^{37}$

Those at risk to others or themselves can often have a wide range of difficulties including substance abuse, housing issues, and legal or financial problems that may be coupled with mental health illness. ${ }^{4,39}$ A variety of services may be required for various aspects of care for each service user, which in turn can create a greater amount of risk to each individual care provider. The system of health care today is so complex that patient safety depends on a range of collaborations and communications between professionals.

Management and care of each service user cannot be solely by appointed to social services, probation, housing, and mental health providers and must be recognized as both a public and personal protection issue that is classified as a concern for all agencies and at all levels. ${ }^{4,41}$ Methods of collaboration should be identified, formed, and strengthened between all service providers which aim to provide improvement and resilience to the effect of violence on public and community safety. The potentially disastrous consequences of failure to do so are well known and documented. Failures in interagency communication and joint working continue to be cited in reports of inquiry into homicides and suicides in the community ( $\mathrm{O}^{\prime}$ Rourke and Hammond $\left.{ }^{4}\right)$. The challenge is to provide evidence-based safe, sound, and supportive risk management for mental health service users, staff, and the wider community.

\section{Discussion}

\section{Evidence-based elements of safer care}

Evidence-based practice implies 3 core bases: Empirical Research, Clinical Expertise and Patient Values, and World View. ${ }^{42,43}$

Public enquiries have noted a lack of evidence-based practice. 
Services can enhance risk management by implementing only evidence-based approaches which involve the application of rigorous, systematic, and objective procedures to obtain reliable and valid knowledge relevant risk and care management activities and programs.

Working from effective baselines is an essential element of safer care; therefore, using only evidence-based protocols and clinical expertise for the assessment and management of risk and care is advised.

The DOH 2007 Best Practice in Risk Management Guidance ${ }^{40}$ helpfully lists risk assessment and management tools that meet the recommended best practice standards and enhance better, safer mental health care. Effective risk assessment and management, which actively involves the service user, can and should be empowering and health promoting.

Improving quality and safety of care is also enabled by clinicians and practitioners identifying best practices, identifying gaps in current practice, developing relevant policies and procedures, and monitoring outcomes through quality and safety, self-assessment, and audit. The NCISH in particular identified the implications for staff training around risk, communication, and documentation procedures.

Clinical governance is a useful tool for assisting quality and safety. It requires action by health providers to ensure 4 major activities as follows:

1. Risks are avoided, safety is built in,

2. Adverse events are rapidly detected, openly investigated, and lessons learned,

3. Good practice is rapidly disseminated, and

4. Systems are in place to ensure continuous improvement in clinical care.

We also need to create a culture of learning, attention to patient safety, and continuous quality improvement in training in which professionals develop both an individual and a systems perspective on the quality of risk and care provision. ${ }^{44}$ This approach can have the confidence of service users, carers, families, clinicians, practitioners, and purchasers of service.

Person-centered care is another evidence-based element of safer care. ${ }^{5}$

Person-centered care is concerned with building a professional and supportive partnership with mental health service users. A program is person-centered when it ensures that patients and health care professionals (eg, the mental health team) work in partnership to ensure:
1. Understanding of both the mental health issues or illness and all dimensions of the illness experience (feelings about being ill, ideas about the disorder, impact of mental health issues on daily life, and expectations of health care pathway)

2. Health care professionals understanding of the whole person and his or her needs (therapist/clinician and patient/ service user together map out how the condition is to be managed)

3. Prevention and health promotion are discussed in partnership from the outset and are supported through attention at each consultation/contact

4. Tools are used to enhance concordance and facilitate good clinician-patient relationship, for example Structured, Measurable, Achievable, Realistic, and Time scaled plans are in place for each patient/service use.

Person-centered care required skills in interpersonal communication, addressing people's health and emotional needs and beliefs, shared decision-making, teaching skills for self-management, self-regulation, and applying principles of primary prevention and behavioral change. Such care requires applying knowledge of cognitive, affective, and contextual bases of behavior to health and social care.

The report and 20 year review of the NCISH summarized other essential evidence-based elements of safer care including safer wards, care planning, and early follow-up; 24 hour crisis or home treatment resources; community outreach and specialist services for alcohol and drug misuse; and dual diagnosis.

\section{Priorities for safer services}

"On the basis of our evidence over 20 years, 2 interventions are crucial: - services for drug and alcohol misuse, and 'dual diagnosis' indicating complex treatment needs and-services to maintain engagement with patients who are likely to lose contact." 38

The first author's clinical experience suggests 2 further priorities for safer service and these are: 1) Listening and working with patient values and world view and 2) Learning the lessons of inquiries and adopting a rigorous learning culture as a way of promoting continuous improvement.

\section{Conclusion}

In conclusion, violence within mental health services is a complex interplay between historical, clinical, dispositional, and contextual factors. Effective risk management 
is crucial to the provision of good quality mental health services. Although risk will never be eliminated completely, it can be minimized by implementing good procedures for measuring and working with risk, within good quality care management.

The gap in quality between what is and what could be is a chasm. Enhancing risk management, it is suggested, can be achieved through the development of a learning culture, learning lessons from inquiries and the NCISH, and through the implementation and application of only evidenced-based, patient-centered practice. In this way, mental health providers can develop priorities for safer services and update or redesign mental health services to provide safe, effective, patient-centered, timely, efficient, and equitable care for this diverse and often vulnerable population.

\section{Disclosure}

The authors report no conflicts of interest in this work.

\section{References}

1. Anderson A, West SG. Violence against mental health professionals: when the treater becomes the victim. Innov Clin Neurosci. 2011;8(3):34-39.

2. Privitera M, Weisman R, Cerulli C, Tu X, Groman A. Violence toward mental health staff and safety in the work environment. Occup Med. 2005;55(6):480-486.

3. Reid RJ, Bonomi AE, Rivara FP, et al. Intimate partner violence among men: prevalence, chronicity, and health effects. Am J Prev Med. 2008;34(6):478-485.

4. O'Rourke M, Hammond S. Risk Management: Towards Safe Sound and Supportive Service. Leatherhead, UK: Surrey Hampshire Borders NHS Trust; 2000.

5. O'Rourke M, Bailes G. Risk Assessment and Management. In: Davies J, editor. Briefing Paper No. 4. Leicester: British Psychological Society; 2006:1-36.

6. Buchanan A, Binder R, Norko M, Swartz M. Psychiatric violence risk assessment. Am J Psychiatry. 2011;169(3):340.

7. Dolan M, Doyle M. Violence risk prediction: clinical and actuarial measures and the role of the psychopathy checklist. Br J Psychiatry. 2000;177:303-311.

8. Lawrie SM. Clinical risk prediction in schizophrenia. Lancet Psychiatry. 2014;1(6):406-408.

9. Bernardini F, Attademo L, Cleary S, et al. Risk prediction models in psychiatry: toward a new frontier for the prevention of mental illnesses. J Clin Psychiatry. 2017;78(5):572-583.

10. Briner M, Manser T. Clinical risk management in mental health: a qualitative study of main risks and related organizational management practices. BMC Health Serv Res. 2011;13:44.

11. Friedman RA. Violence and mental illness - how strong is the link? N Engl J Med. 2006;355(20):2064-2066.

12. Erdos BZ, Hughes DH. Emergency psychiatry: a review of assaults by patients against staff at psychiatric emergency centers. Psychiatr Serv. 2001;52(9):1175-1177.

13. Rueve ME, Welton RS. Violence and mental illness. Psychiatry (Edgmont). 2008;5(5):34-48.

14. Littlechild B. Violence and Aggression: Short-term Management in Mental Health, Health and Community Settings. NICE Guideline. London: National Institute for Health and Care Excellence; 2015.
15. NHS England. Focus on Staff Experience National NHS Staff Survey 2014. Oxford: The Co-ordination Centre, Picker Institute Europe; 2014.

16. Popay J, Rogers A, Williams G. Rationale and standards for the systematic review of qualitative literature in health services research. Qual Health Res. 1998;8(3):341-351.

17. Smith V, Devane D, Begley CM, Clarke M. Methodology in conducting a systematic review of systematic reviews of healthcare interventions. BMC Med Res Methodol. 2011;11(1):15.

18. National Collaborating Centre for Mental Health (UK). Violence and Aggression: Short-Term Management in Mental Health, Health and Community Settings: Updated Edition. London: British Psychological Society; 2015. (NICE Guideline, No. 10). Available from: https:// www.ncbi.nlm.nih.gov/books/NBK356335/. Accessed May 24, 2018.

19. Bowers L, Stewart D, Papadopoulos C, Dack C, Ross J, Khanom H. Inpatient violence and aggression: a literature review. Report from the Conflict and Containment Reduction Research Programme. London: Institute of Psychiatry, Kings College London; 2011.

20. Winstanley S, Whittington R. Aggression towards health care staff in a UK general hospital: variation among professions and departments. J Clin Nurs. 2004;13(1):3-10.

21. Gates DM, Ross CS, McQueen L. Violence against emergency department workers. J Emerg Med. 2006;31(3):331-337.

22. Holmes D, Rudge T, Perron A, editors. (Re)Thinking Violence in Health Care Settings: A Critical Approach. Farnham, UK: Ashgate Publishing, Ltd; 2011.

23. Alaszewsk, A, Harrison L, Manthorpe J, editors. Risk, Health and Welfare: Policies, Strategies and Practice. Buckingham: Open University Press; 1998.

24. Gillespie GL, Pekar B, Byczkowski TL, Fisher BS. Worker, workplace, and community/environmental risk factors for workplace violence in emergency departments. Arch Environ Occup Health. 2017;72(2):79-86.

25. Jackson JL, Mallory R. Aggression and violence among elderly patients, a growing health problem. J Gen Intern Med. 2009;24(10): $1167-1168$.

26. Stathopoulou HG. Violence and aggression towards health care professionals. Health Sci J. 2007;2:1-7.

27. International Labor Office. Workplace violence in the health care sector. Geneva: International Labor Office; 2002. Available from: http://www. iol.org. Accessed May 24, 2018.

28. Dickens G, Picchioni M, Long C. Aggression in specialist secure and forensic inpatient mental health care: incidence across care pathways. J Forensic Pract. 2013;15(3):206-217.

29. Uppal G, McMurran M. Recorded incidents in a high-secure hospital: a descriptive analysis. Crim Behav Ment Health. 2009;19(4):265-276.

30. O'Beirne M, Gabe J. Reducing violence against NHS staff: findings from an evaluation of the Safer Surrey Hospital Initiative. Crime Prev Community Saf. 2005;7(2):29-39.

31. Rowe A, Haywood J. Providing Effective Supervision: A Workforce Development Tool, Including a Unit of Competence and Supporting Guidance. Leeds: Skills for Care and the Children's Workforce Development Council; 2007.

32. Health and Safety Executive. Social care workers exposed to violence and aggression. Bootle: Health and Safety Executive; 2012. Contract No.: Release No.: NE/008/12.

33. Pahl J. Coping with physical violence and verbal abuse In: Balloch S, McLean J, Fisher M, editors. Social Services Working Under Pressure. Bristol: The National Institute of Social Work and the Policy Press; 1999:87-106.

34. Keogh P, Byrne C. Crisis, Concern and Complacency: A Study on the Extent, Impact and Management of Workplace Violence and Assault on Social Care Workers. Ireland: Social Care; 2016.

35. Health Service Executive. Risk Management in Mental Health. Guidance Document. Dublin, Ireland: Health Service Executive and Clinical Indemnity Scheme; 2010.

36. Parker $\mathrm{C}, \mathrm{McCulloch} \mathrm{A}$. Key Issues from Homicide Inquiries. London: MIND; 1999. 
37. Munroe E, Rumgay J. Role of risk assessment in reducing homicides by people with mental illness. Br J Psychiatry. 2000;176(2):116-120.

38. Appleby L, Kapur N, Shaw J, et al. The National Confidential Inquiry into Suicide and Homicide by People with Mental Illness: Making Mental Health Safer. Annual Report and 20 year Review. Manchester: University of Manchester; 2016.

39. National Confidential Inquiry into Suicide and Homicide by People with Mental Illness. In-Patient Suicide Under Observation. Manchester: University of Manchester; 2015. Available from: www.bbmh.manchester ac.uk/cmhs/research/centreforsuicideprevention/nci/reports. Accessed May 24, 2018.

40. Department of Health, National Risk Management Programme. Best Practice in Managing Risk. London: National Risk Management Programme; 2007.

41. Hunt IM, Rahman MS, While D, et al. Safety of patients under the care of crisis resolution home treatment services in England: a retrospective analysis of suicide trends from 2003 to 2011. Lancet Psychiatry. 2014;1(2):135-141.

42. APA Presidential Task Force on Evidence-Based Practice. Evidencebased practice in psychology. Am Psychol. 2006;61(4):271-285.

43. Kelly MP, Heath I, Howick J, Greenhalgh T. The importance of values in evidence-based medicine. BMC Med Ethics. 2015;16(1):69.

44. O’Rourke M. Start Safe Stay Safe: A Handbook for Suicide Prevention, Violence Reduction and Risk Management. London: RAMAS; 2003.
45. Bureau of Labor Statistics. Workplace Violence: Guidelines for Preventing Workplace Violence for Healthcare and Social Service Workers. OSHA Publication No. 3148, 2014. Available from: https:/www.osha. gov/Publications/osha3148.pdf. Accessed February, 2018.

46. United States Department of Labor. Census of Fatal Occupational Injuries. Bureau of Labor Statistics, 2000. Available from: https://www. bls.gov/iif/oshcfoiarchive.htm. Accessed February, 2018.

47. Goodman RA, Jenkins EL, Mercy JA. Workplace-related homicide among health care workers in the United States, 1980 through 1990. JAMA. 1994;272(21):1686-1688.

48. Bureau of Labor Statistics. Workplace Violence. 2010. Retrieved from https:/www.osha.gov/SLTC/healthcarefacilities/violence.html. Accessed February, 2018.

49. Warchol G. Workplace violence, 1992-96: Bureau of Justice Statistics Special Report. Pub NCJ, 168634. 1998.

50. Health and Safety Executive. Violence at Work, 2015/16; Findings from the Crime Survey for England and Wales and from RIDDOR. 2016. Available from: http:/www.hse.gov.uk/statistics/causinj/violence/ violence-at-work.pdf. Accessed February, 2018.

51. Health and Safety Executive. Violence at Work: New Findings from the British Crime Survey. 2000. Available from: http://www.hse.gov.uk/ violence/britishcrimesurvey.pdf. Accessed February, 2018.
Risk Management and Healthcare Policy

\section{Publish your work in this journal}

Risk Management and Healthcare Policy is an international, peer-reviewed open access journal focusing on all aspects of public health, policy, and preventative measures to promote good health and improve morbidity and mortality in the population. The journal welcomes submitted papers covering original research, basic science, clinical and epidemiological

\section{Dovepress}

studies, reviews and evaluations, guidelines, expert opinion and commentary, case reports and extended reports. The manuscript management system is completely online and includes a very quick and fair peerreview system, which is all easy to use. Visit http://www.dovepress.com/ testimonials.php to read real quotes from published authors.

Submit your manuscript here: https://www.dovepress.com/risk-management-and-healthcare-policy-journal 